TI 2014-006/VI

Tinbergen Institute Discussion Paper

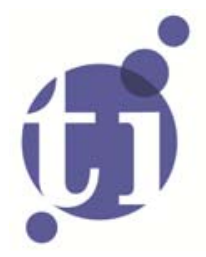

\title{
Fiscal and Monetary Policy Coordination, Macroeconomic Stability, and Sovereign Risk
}

\author{
Dennis Bonam' \\ Jasper Lukkezen²
}

1 Faculty of Economics and Business Administration, VU University Amsterdam, and Tinbergen Institute, The Netherlands;

2 Utrecht University, Utrecht, and CPB Netherlands Bureau for Economic Policy Analysis, The Hague, The Netherlands. 
Tinbergen Institute is the graduate school and research institute in economics of Erasmus University Rotterdam, the University of Amsterdam and VU University Amsterdam.

More TI discussion papers can be downloaded at http://www.tinbergen.nl

Tinbergen Institute has two locations:

Tinbergen Institute Amsterdam

Gustav Mahlerplein 117

1082 MS Amsterdam

The Netherlands

Tel.: +31(0)205251600

Tinbergen Institute Rotterdam

Burg. Oudlaan 50

3062 PA Rotterdam

The Netherlands

Tel.: +31(0)10 4088900

Fax: $+31(0) 104089031$

Duisenberg school of finance is a collaboration of the Dutch financial sector and universities, with the ambition to support innovative research and offer top quality academic education in core areas of finance.

DSF research papers can be downloaded at: http://www.dsf.nl/

Duisenberg school of finance

Gustav Mahlerplein 117

1082 MS Amsterdam

The Netherlands

Tel.: +31(0)20 5258579 


\title{
Fiscal and monetary policy coordination, macroeconomic stability, and sovereign risk*
}

\author{
Dennis Bonam ${ }^{\S} \quad$ Jasper Lukkezen $₫$
}

19th December 2013

\begin{abstract}
In standard macroeconomic models, debt sustainability and price level determinacy are achieved when fiscal policy avoids explosive debt and monetary policy controls inflation, irrespective of the relative strengths of each policy stance. We examine how these policy requirements for equilibrium stability and determinacy change in the presence of sovereign risk. An increase in sovereign risk reduces lender's willingness to hold government debt and raises consumption and inflation. Therefore, inflation and debt dynamics are determined jointly. To ensure stable macroeconomic conditions, both the fiscal and monetary stance must shift to offset debt sustainability concerns. We find that the adoption of a deficit target helps alleviate such concerns and raises the scope for macroeconomic stability.
\end{abstract}

JEL Classification: E52, E62, E63

Keywords: Fiscal and monetary policy coordination, equilibrium determinacy and stability, sovereign risk, policy rules

*We like to thank Bart Hobijn, David Hollanders, Christiaan van der Kwaak and seminar participants at the Nederlandse Economendag 2013, Utrecht University and CPB for comments. All errors are our own.

${ }^{\S}$ Corresponding author. VU University Amsterdam and Tinbergen Institute; Email: d.a.r.bonam@vu.nl.

"Utrecht University and CPB Netherlands Bureau for Economic Policy Analysis; E-mail: j.h.j.lukkezen@cpb.nl. 


\section{Introduction}

In most economies, macroeconomic stabilisation policy is characterised by a division of tasks between the central bank and the government: the central bank maintains price stability by setting the policy rate according to an inflation target, whereas the government ensures fiscal solvency through appropriate adjustments in the budget surplus. In principle, as long as monetary policy obeys the Taylor-principle, such that the policy rate rises by more than one-for-one with inflation, and fiscal policy prevents debt from growing without bounds, a stable and unique equilibrium can be achieved. As shown in Leeper (1991), this result arises regardless of the relative strengths of each policy stance; in fact, the monetary requirements for price stability are independent from the fiscal requirements for debt sustainability, and vice versa.

However, in times of sovereign debt crises, we typically find governments being forced to take on a more austere stance, in order to obtain sustainable levels of debt, while central bankers raise their concerns regarding runaway inflation. Our objective in this paper is to reveal the rationale underlying these shifts in fiscal and monetary policy following an increase in debt sustainability concerns. In particular, we examine how sovereign risk affects the stabilising properties of fiscal and monetary policy and the constraints imposed by macroeconomic stability on the interaction between the government and central bank.

Our point of departure is a closed endowment economy in which policy makers follow simple feedback rules and in which we allow for the possibility of sovereign default. In particular, we assume fiscal policy is characterised by a rule that relates the primary budget surplus to changes in the real value of outstanding debt and the budget deficit, whereas monetary policy is described by an interest rate rule, relating the short-term nominal interest rate to current inflation. Sovereign default risk is introduced through a stochastic "fiscal limit", along the lines of Davig et al. (2011) and $\mathrm{Bi}$ (2012), which reflects the maximum level of debt the government is willing or able to service; expectations of sovereign default then arise whenever the outstanding stock of debt approaches this fiscal limit. Throughout, we shall discuss the results within the context of this simple endowment economy model

for analytical simplicity. Nevertheless, our results generalise to a more elaborate model with endogenous production, nominal rigidities and distortionary taxation. The interested reader is referred to the Appendix, in which we demonstrate this generalisation.

When the risk of sovereign default is absent, we re-obtain the results of Leeper (1991) and show that equilibrium outcomes are determined by the policy regime (i.e. the combination of the fiscal and monetary stance). Also, since the equilibrium paths for inflation and government debt can be decoupled, the stability and determinacy requirements imposed on monetary policy are independent from fiscal policy, and vice versa. Hence, stable macroeconomic conditions can be obtained, irrespective of the relative fiscal-monetary stance. Further, we show that alternative fiscal objectives, other than those pertaining to long-run fiscal solvency, do not affect the ability of the fiscal and monetary authorities to deliver stable and unique equilibria.

These results change markedly, however, when the level of government debt rises to unsustainable levels. Specifically, an increase in the probability of sover- 
eign default reduces the effective real rate of return on government bonds, inducing private lenders to reduce their holdings of bonds and raise consumption, which in turn pushes up the price level. Inflation and debt dynamics can thus no longer be determined separately and the standard requirements for macroeconomic stability change. We demonstrate that the monetary stance required to uniquely determine the price level is no longer dictated solely by the Taylor-principle, yet is also a function of the fiscal stance. Similarly, the fiscal stance required to ensure debt sustainability now depends on the monetary stance as well. Therefore, in the presence of sovereign risk, it is the relative policy stance, rather than the policy regime, which determines equilibrium outcomes.

We find that the likelihood of obtaining unstable and indeterminate equilibria increases when the government is unable (or unwilling) to commit to a deficit target. Under such 'weak' fiscal objectives, the government essentially allows for short-run budget deficits, which raises the probability of sovereign default and lowers the return on bonds. The subsequent rise in consumption and inflation prompts the central bank to increase the interest rate, which raises public interest expenses and thereby also the budget deficit and the stock of government debt. Hence, expectations become self-fulfilling and the economy falls into a cycle of rising debt and inflation. To deliver stable macroeconomic outcomes, the government must respond more austerely to increases in public debt, so as to signal its commitment to fiscal solvency, and/or the central bank must offset the decline in the return on bonds through an increase in the bonds rate so as to induce lenders to hold government debt in equilibrium. However, when the government adopts a deficit target, and raises the budget surplus in response to higher deficits, macroeconomic stability can be obtained more easily. In particular, the deficit target alleviates debt sustainability concerns, which in turn lowers the probability of sovereign default and, through a reduction in consumption, also the rate of inflation. Hence, by committing itself to maintain low budget deficits, the government accommodates monetary policy in keeping inflation low and the equilibrium stability and determinacy requirements for both fiscal and monetary policy are relaxed. In fact, we show that price level determinacy can be achieved even when monetary policy violates the Taylor-principle.

Our analysis falls within the literature on the relationship between macroeconomic stabilisation policy and debt non-neutrality. In most studies, debt nonneutrality arises either from transaction services (Canzoneri and Diba, 2005; Linnemann and Schabert, 2012) or wealth effects (in models of finitely lived agents) generated by government bonds (Piergallini, 2005; Leith and von Thadden, 2008). However, Bi et al. (2010) and Schabert and van Wijnbergen (2011) investigate the implications of debt non-neutrality arising from sovereign risk. Whereas these studies examine the effects of monetary and fiscal policy shocks on debt and price level variability in times of sovereign risk, we focus on the implications of alternative fiscal objectives for the ability of fiscal and monetary policy to achieve stable macroeconomic conditions. Another related paper is Uribe (2006), in which the monetary implications of endogenous sovereign default are examined within the context of exogenous fiscal policy. We differ fundamentally from Uribe (2006) by assuming fiscal policy is determined endogenously, whereas sovereign default is modelled exogenously.

The rest of the paper is organised as follows. In section 2 , we outline the the- 
oretical model. In Section 3, we derive analytical expressions for the equilibrium stability and determinacy requirements for fiscal and monetary policy and examine how sovereign risk affects those requirements. Section 4 then discusses how the central bank can undo the effects of sovereign risk. Finally, Section 5 concludes.

\section{A dynamic model with sovereign risk}

In this section, we describe the dynamic model we use for our main analysis. For the sake of comparability and analytical convenience, our framework is closely related to the closed endowment economy of Leeper (1991, henceforth Leeper). The model consists of households that consume and invest in government bonds, a fiscal authority that levies taxes and issues debt to cover public spending, and a monetary authority that targets inflation. In order to stay in line with conventional New Keynesian models, we differ from Leeper by assuming a cashless economy (see Bi et al., 2010 and other recent work by Leeper). Furthermore, we extend the model by including two key features: the possibility of sovereign default and a rich set of policy feedback rules.

\subsection{Households}

A representative, infinitely-lived household chooses the optimal level of consumption, $c_{t}$, to maximise expected life-time utility, i.e.

$$
E_{0} \sum_{k=0}^{\infty} \beta^{k} \log c_{t+k},
$$

where $\beta \in(0,1)$ is the household's discount factor and $E_{t}$ is the expectations operator conditional on information available at $t$. The household receives a constant endowment of $y$ units in each period, pays lump-sum net taxes, $\tau_{t}$, to the fiscal authority and carries wealth from one period to the next by investing in one-period, nominal government discount bonds, $B_{t}$, on which it receives the bonds rate, $R_{t}-1$, conditional on the probability of sovereign default. The household's (perceived) budget constraint is given by:

$$
P_{t} c_{t}+B_{t}+P_{t} \tau_{t}=P_{t} y+\left(1-\delta_{t}\right) R_{t-1} B_{t-1},
$$

where $P_{t}$ is the price level and $\delta_{t} \in[0,1)$ the sovereign default probability, which shall be discussed in more detail below.

Subject to (2) and an appropriate transversality condition and taking prices, the endowment, the tax rate, the sovereign default probability and initial asset holdings, $B_{-1}$, as given, the household maximises (1), which leads to the following optimal intertemporal condition:

$$
c_{t}^{-1}=\beta E_{t}\left[\left(1-\delta_{t+1}\right) \frac{R_{t}}{\pi_{t+1}} c_{t+1}^{-1}\right] .
$$

where $\pi_{t} \equiv P_{t} / P_{t-1}$ is the gross rate of inflation. Equation (3) gives the household's Euler equation, which relates expected consumption growth to the effective real rate of return on government bonds. Note that the steady-state gross real interest rate, $R / \pi$, is determined by $1 /[\beta(1-\delta)]$ and is strictly larger than the gross riskfree real interest rate, $1 / \beta$, for $\delta>0$. 


\subsection{Public sector}

The public sector consists of a fiscal authority ("government") and a monetary authority ("central bank"), each acting independently from each other. The government consumes an amount $g_{t}$, levies lump-sum taxes, $\tau_{t}$, and issues nominal bonds, $B_{t}$, on which it must pay the gross nominal interest rate $R_{t}$. The central bank sets the policy rate through the sale and purchase of government securities.

Assuming constancy of government consumption, i.e. $g_{t}=g$ for all $t$, the government's (perceived) budget constraint, in real terms, is given by:

$$
b_{t}+\tau_{t}=g+\left(1-\delta_{t}\right) \frac{R_{t-1}}{\pi_{t}} b_{t-1},
$$

where $b_{t} \equiv B_{t} / P_{t}$ is the real value of government debt.

\subsubsection{Modelling sovereign default}

An important feature of the model is the government's ability to default on its debt. A number of recent contributions have examined the implications of sovereign default risk for inflation and output volatility and the efficacy of monetary policy, e.g. Davig et al. (2010), and for the relationship between the debt-to-output ratio and interest rates, e.g. Bi (2012). In these studies, sovereign risk arises through the presence of a so-called "fiscal limit", i.e. an upper bound to the level of government debt that is economically or politically feasible; beyond the fiscal limit, the government defaults. ${ }^{1}$

In the present model, we follow a similar approach. However, unlike in the aforementioned studies, in which the focus lies on the interaction between the economy and the fiscal limit and in which the limit is modelled endogenously, our fiscal limit is determined exogenously. Particularly, since we are concerned with the effects of sovereign risk on the equilibrium determinacy and stability requirements regardless of how the fiscal limit is reached, we require only that a fiscal limit exists, that the default probability is positively related to the level of government debt and that all agents act on their assessment of the default probability.

To this end, we assume that the probability of a sovereign default occurring at $t$, denoted by $\delta_{t}$, is determined by a function which is increasing in the real level of gross government liabilities, i.e.:

$$
\delta_{t}=H\left(\frac{R_{t-1}}{\pi_{t}} b_{t-1}\right)
$$

where $H(-\infty)=0, H(\infty)=1$ and $d H(x) / d x>0$ for all $x$.

\subsubsection{Specification of policy rules}

Another important feature of the model is the characterisation of the policy regime and policy stance by simple feedback rules. We define a "policy regime" as a particular combination of the fiscal and monetary stance. As in Leeper, and many others

\footnotetext{
${ }^{1}$ See Eaton and Gersovitz (1981) for a political economy model in which the fiscal limit arises through strategic decisions by the government and Bi (2012) for an example in which the fiscal limit arises from the constraints imposed by the economy's Laffer curve on the sovereign's ability to service debt.
} 
that have examined the interaction between fiscal and monetary policy in dynamic macroeconomic models, we describe the fiscal and monetary stance using "policy rules". Policy rules can be thought of as reduced form representations of complex political or institutional negotiation processes. To explicitly model such processes in a full-fledged political economy framework is an attractive extension, yet beyond the scope of the present paper.

Following Linnemann (2006) and Collignon (2012), we assume that the government obeys the following rule:

$$
p s_{t}=\tilde{\gamma}_{b}\left(b_{t-1}-b^{*}\right)+\tilde{\gamma}_{d}\left(d_{t}-d^{*}\right)+\left(\frac{1}{\beta}-1\right) b,
$$

where $p s_{t} \equiv \tau_{t}-g$ is the primary budget surplus, $d_{t} \equiv g+\left(R_{t-1}-1\right) b_{t-1}-\tau_{t}$ the (secondary) budget deficit and $b^{*}$ and $d^{*}$ denote target levels for real government debt and the budget deficit, respectively. The last term on the right-hand side of (5) is a constant that ensures a positive steady-state level of real debt. Together, the parameters $\tilde{\gamma}_{b}$ and $\tilde{\gamma}_{d}$ summarise the fiscal policy stance.

Let variables without a $t$ subscript denote the corresponding steady-state level and variables with a hat the percentage deviation from steady state, i.e. $\hat{x}_{t} \equiv$ $\left(x_{t}-x\right) / x$ for any generic variable $x_{t}$. Then, log-linearisation of (5) yields:

$$
\hat{\tau}_{t}=\frac{b}{\tau}\left(\gamma_{b} \hat{b}_{t-1}+\gamma_{d} \hat{R}_{t-1}\right)
$$

where $\gamma_{b} \equiv\left[\widetilde{\gamma}_{b}+\widetilde{\gamma}_{d}(R-1)\right] /\left(1+\widetilde{\gamma}_{d}\right)$ and $\gamma_{d} \equiv \widetilde{\gamma}_{d} R /\left(1+\widetilde{\gamma}_{d}\right)$. The parameter $\gamma_{b}$ measures the government's response to changes in the outstanding level of real debt and thus its control over debt dynamics. Following Leeper, we shall characterise the fiscal policy stance based on the following definition:

Definition 1. The fiscal policy stance is called "passive" if $\gamma_{b}>1 / \beta-1$. Otherwise, it is called "active".

Recall that $1 / \beta-1$ is the real risk-free interest rate in steady state. Hence, when fiscal policy is passive, the government aims at preventing debt from growing faster than the real risk-free rate, which stabilises debt in the long run; conversely, an active fiscal policy is inconsiderate of long-run government debt dynamics and debt may not be stable in equilibrium.

The government's response to changes in the budget deficit is implied by its marginal response to changes in the nominal interest rate and is measured by the parameter $\gamma_{d}$. If $\gamma_{d}>0$, the government adjusts taxes upward upon an increase in the interest rate, such that the actual budget deficit increases by less than one-forone with the interest rate and, eventually, converges towards its target level, $d^{*}$. A fiscal stance characterised by $\gamma_{d}>0$ therefore implicitly encompasses a "deficit target". It shall prove to be convenient to define the following:

Definition 2. Fiscal policy is called "strong" if $\gamma_{d}>0$. Otherwise, it is called "weak".

Note that one could also interpret $\gamma_{d}$ as reflecting the government's choice between counter- and pro-cyclical fiscal policy. Intuitively, when the economy faces a downturn, during which tax revenues fall and government spending rises through 
automatic stabilisers, the budget deficit rises. Then, if $\gamma_{d}<0$, the government allows the deficit to rise even further in an attempt to stimulate aggregate demand; hence, fiscal policy is said to be countercyclical. Conversely, if the government aims to reduce deficits, despite the decline in economic activity, it sets $\gamma_{d}>0$ and raises the budget surplus, in which case fiscal policy is said to be pro-cyclical.

Regarding monetary policy, we assume the central bank obeys a Taylor-type rule (Taylor, 1993), which relates the nominal interest rate to changes in contemporary inflation:

$$
R_{t}=\widetilde{\alpha}_{\pi}\left(\pi_{t}-\pi^{*}\right),
$$

where $\pi^{*}$ is the inflation target. The parameter $\widetilde{\alpha}_{\pi}>0$ measures the aggressiveness with which the central bank responds to inflation and thus determines the monetary stance.

Log-linearisation of (7) yields:

$$
\hat{R}_{t}=\alpha_{\pi} \hat{\pi}_{t},
$$

where $\alpha_{\pi} \equiv \tilde{\alpha}_{\pi} \pi / R$. If $\alpha_{\pi}>1$, the central bank satisfies the familiar Taylorprinciple whereby it raises the policy rate by more than one-for-one with changes in inflation. Again, we follow the terminology of Leeper to characterise the monetary policy stance:

Definition 3. The monetary policy stance is called "active" if $\alpha_{\pi}>1$. Otherwise, it is called "passive".

Note that we assumed that the interest rate controlled by the central bank equals the interest rate on government bonds. This assumption seems reasonable, as central banks often execute monetary policy through open market operations on the government bonds market. Furthermore, monetary policy rules of the form (8) are among the most dominant in the literature (for an overview, see Clarida et al., 1999).

\subsection{Equilibrium}

In equilibrium, the economy's aggregate resource constraint, $y=c_{t}+g$, must be satisfied, implying $c_{t}=c$ for all $t$, and the government bonds market clears.

Equilibrium is then given by a sequence of $b_{t+k}, \delta_{t+k}, \pi_{t+k}, \tau_{t+k}$ and $R_{t+k}$, satisfying the household's Euler equation, (3), the government's budget constraint, (4), the two policy rules, (5) and (7), and exogenous sequences for the endowment, $y$, government consumption, $g$, and the fiscal limit, for all $k$.

\section{Requirements for stability and determinacy}

In this section, we discuss those policy stances under which debt sustainability and price level determinacy are (not) achieved in equilibrium. We start by reducing the log-linearised version of the model to a manageable system of two equations. Next, we discuss the equilibrium stability and determinacy requirements for the fiscal and monetary stance in the absence of sovereign risk. This case serves as 
a benchmark and, as shall be shown, reproduces the results of Leeper. Finally, we discuss how the constraints imposed by macroeconomic stability on fiscal and monetary policy change after introducing sovereign risk.

\subsection{Dynamics of the model}

We represent the dynamics of the model around the deterministic steady state in log-linearised form. First, we log-linearise the probability of no-default, i.e. $1-\delta_{t}$, as follows:

$$
\begin{aligned}
1-\delta_{t} & \approx(1-\delta)-H^{\prime}\left(\frac{R_{t-1}}{\pi_{t}} b_{t-1}-\frac{R}{\pi} b\right) \\
\frac{\left(1-\delta_{t}\right)-(1-\delta)}{1-\delta} & \approx-H^{\prime} \frac{\frac{R}{\pi} b}{1-\delta}\left(\frac{\frac{R_{t-1}}{\pi_{t}} b_{t-1}-\frac{R}{\pi} b}{\frac{R}{\pi} b}\right) \\
& =-\Phi\left(\hat{R}_{t-1}-\hat{\pi}_{t}+\hat{b}_{t-1}\right)
\end{aligned}
$$

where $\Phi \equiv H^{\prime}(R / \pi) b /(1-\delta)$ is the elasticity of the sovereign default probability with respect to gross public debt, and can therefore be interpreted as the 'degree of sovereign risk' (see Schabert and van Wijnbergen, 2011). Second, using (9) we loglinearise the household's Euler equation and the government's budget constraint to obtain:

$$
\begin{aligned}
0 & =\hat{R}_{t}-E_{t} \hat{\pi}_{t+1}-\tilde{\Phi} \hat{b}_{t} \\
\hat{b}_{t}+\frac{\tau}{b} \hat{\tau}_{t} & =\left(\frac{1-\Phi}{\beta}\right)\left(\hat{R}_{t-1}-\hat{\pi}_{t}+\hat{b}_{t-1}\right),
\end{aligned}
$$

where $\tilde{\Phi}=\Phi /(1-\Phi)$. The full log-linearised version of the model then consists of Equations (10), (11), (6) and (8) and, after appropriate substitutions, can be reduced to a $2 \times 2$ system in the endogenous variables $\left\{\hat{\pi}_{t}, \hat{b}_{t}\right\}$ :

$$
\left[\begin{array}{c}
E_{t} \hat{\pi}_{t+1} \\
\hat{b}_{t}
\end{array}\right]=A\left[\begin{array}{c}
\hat{\pi}_{t} \\
\hat{b}_{t-1}
\end{array}\right]
$$

where

$$
A \equiv\left[\begin{array}{cc}
\alpha_{\pi}+\tilde{\Phi} \gamma_{d} & -\tilde{\Phi}\left(\frac{1}{\beta}-\gamma_{b}-\gamma_{d} \tilde{\Phi}\right) \\
-\gamma_{d} & \frac{1}{\beta}-\gamma_{b}-\gamma_{d} \tilde{\Phi}
\end{array}\right] .
$$

The system described by (12) has one forward-looking variable, $\hat{\pi}_{t}$, and one predetermined variable, $\hat{b}_{t}$. Therefore, the matrix $A$ should contain exactly one stable eigenvalue (i.e. smaller than modulus one), to obtain debt sustainability, and one unstable eigenvalue (i.e. larger than modulus one), to derive price level determinacy. If there are too many unstable eigenvalues, then either the system has no solution or equilibrium is non-stationary due to explosive paths for government debt; if there are too few unstable eigenvalues, the system has infinitely many solutions and admits the possibility of sunspot shocks affecting equilibrium allocations such that the price level sequence is indeterminate (see Blanchard and Kahn, 1980). 


\subsection{Reproducing Leeper (1991)}

The conditions under which the fiscal and monetary policy stance deliver debt sustainability and price level determinacy in the absence of sovereign risk are given by the following proposition:

Proposition 1. Given $\Phi=0$, a fiscal rule of the form (5) and a monetary rule of the form (7), a stable and unique rational expectations equilibrium is obtained if and only if (i) monetary policy is active and fiscal policy is passive or (ii) monetary policy is passive and fiscal policy is active. Formally, either:

$$
\begin{aligned}
& \text { 1. } \alpha_{\pi}>1 \text { and } \gamma_{b}>\frac{1}{\beta}-1 \text {; or } \\
& \text { 2. } \alpha_{\pi}<1 \text { and } \gamma_{b}<\frac{1}{\beta}-1 \text {. }
\end{aligned}
$$

Proof. For a stable and unique solution to the system described by (12), one eigenvalue of $A$ must be larger than modulus one and one eigenvalue must be smaller than modulus one. For $\xi_{i}$ the eigenvalues of $A$, with $i=1,2$, the necessary condition is therefore $\left(\xi_{1}-1\right)\left(\xi_{2}-1\right)<0$ or $\xi_{1} \xi_{2}-\left(\xi_{1}+\xi_{2}\right)=\operatorname{det}(A)-\operatorname{trace}(A)<-1$. For $\Phi=0, A$ reduces to

$$
A=\left[\begin{array}{cc}
\alpha_{\pi} & 0 \\
-\gamma_{d} & \frac{1}{\beta}-\gamma_{b}
\end{array}\right]
$$

Therefore, we can write the necessary condition as $\alpha_{\pi}\left(1 / \beta-\gamma_{b}\right)-\left(\alpha_{\pi}+1 / \beta-\gamma_{b}\right)<$ -1 . Solving for $\alpha_{\pi}$ and $\gamma_{b}$ then proofs the proposition.

The intuition underlying Proposition 1 is discussed next and is illustrated by Figure 1, which shows the number of unstable eigenvalues of $A$ as a function of the fiscal and monetary policy stance (which are governed, respectively, by the parameters $\gamma_{b}$ and $\alpha_{\pi}$ ). In the black area, matrix $A$ has zero unstable eigenvalues, which implies the price level is not uniquely determined ('Indeterminacy'). In the grey area, there is one unstable eigenvalue and equilibrium is characterised by both price level determinacy and debt sustainability ('Stable and unique'). In the white area, there are two unstable eigenvalues, suggesting debt dynamics are unstable ('Instability'). The (blue) dashed lines denote the separation between active and passive monetary and fiscal policy. Hence, each block in the figure corresponds to a different policy regime.

As shown by Figure 1, there are two regions in which debt is sustainable and the price level determinate. In the top-right region, monetary policy is active while fiscal policy is passive. To see how this combination of monetary and fiscal policy delivers stable and unique equilibria, consider a given sunspot shock to inflation. Since monetary policy is active, the central bank raises the nominal interest rate by more than one-for-one with inflation, causing the real interest to go up. As aggregate demand is suppressed by the higher real interest rate, inflation gradually falls back towards its steady-state level and the central bank successfully pins down the price level. The higher interest rate also drives up public interest expenses, which raises the deficit and government debt. Since fiscal policy is passive, the government responds by increasing the primary budget surplus so as to prevent the debt level from growing faster than the steady-state risk-free real interest rate and, thus, to achieve long-run debt sustainability. This particular regime of 
Figure 1: The fiscal-monetary dichotomy: equilibrium outcome as a function of the fiscal and monetary policy stance, without sovereign risk

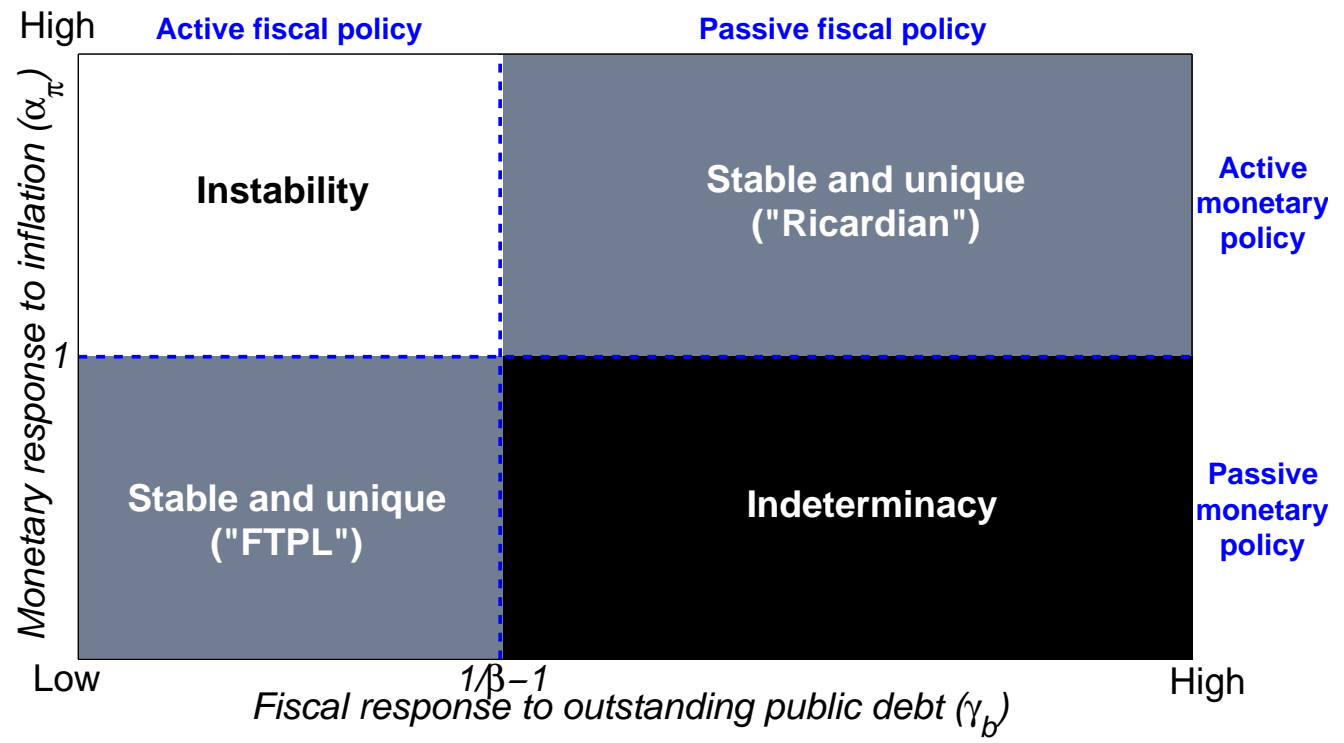

Notes: Figure displays the number of unstable eigenvalues of $A$ as a function of $\gamma_{b}$ and $\alpha_{\pi}$ for $\Phi=0$ and $\beta=0.9926$ : white $=2$, grey $=1$ and black $=0$.

active monetary and passive fiscal policy is often assumed in conventional macroeconomic models, in which the central bank obeys the Taylor-principle and the government is Ricardian (according to the terminology of Woodford, 2001) and satisfies its intertemporal budget constraint endogenously. We therefore refer to the region associated with this policy regime as "Ricardian". In the other region encompassing stable and unique equilibria, monetary policy is passive and fiscal policy active (lower-left block). With active fiscal policy, debt can grow without bounds. To prevent such explosive dynamics, the central bank must allow the price level to 'jump' to a level high enough such that the real value of debt falls to a level at (or below) the discounted value of current and future budget surpluses. In this scenario, monetary policy must therefore be passive to deliver both long-run debt sustainability and price level determinacy. This regime of passive monetary and active fiscal policy corresponds to the Fiscal Theory of the Price Level, in which the price level is effectively determined by public finances and the need to satisfy the government's intertemporal budget constraint (see, among others, Sims, 1994). Hence, we refer to the region associated with this regime as "FTPL".

Note that, when monetary and fiscal policy are both passive, fiscal solvency is obtained for an infinite number of price level sequences and hence equilibrium is left indeterminate. On the other hand, when both policies are active, the price level is determinate, yet, without appropriate adjustments in the budget surplus, government debt becomes explosive.

The results from the benchmark case are identical to those found in Leeper and bring forth a number of important policy implications. First, equilibrium outcomes depend on the policy regime upon which the central bank and the government have coordinated, rather than the relative policy stance. For instance, as long as 
monetary policy is active and fiscal policy passive, one can realise a stable and unique equilibrium. Figure 1 makes clear that this result holds, regardless of the passiveness of fiscal policy or the activeness of monetary policy, resulting in what we define as a "dichotomy" between fiscal and monetary policy. Second, equilibrium outcomes are independent from the nature of alternative fiscal objectives, other than those concerning long-run debt sustainability. In particular, as shown by Proposition 1, the parameter $\gamma_{d}$, which governs the public's stance regarding the budget deficit, does not enter the stability and determinacy requirements for fiscal and monetary policy. Therefore, whether or not fiscal policy is weak or strong is irrelevant for the determination of equilibrium outcomes.

We now turn to the case in which we allow for sovereign default and examine how this affects the results from the benchmark case.

\subsection{Implications of sovereign risk}

The policy requirements for equilibrium stability and determinacy in the presence of sovereign risk are given by the following proposition:

Proposition 2. Given $\Phi \in(0,1)$, a fiscal rule of the form (5) and a monetary rule of the form (7), a stable and unique rational expectations equilibrium is obtained if and only if the policy parameters $\alpha_{\pi}$ and $\gamma_{b}$ obey either:

$$
\begin{aligned}
& \text { 1. } \alpha_{\pi}>1+\frac{\tilde{\Phi} \gamma_{d}}{\frac{1}{\beta}-1-\gamma_{b}-\gamma_{d} \tilde{\Phi}} \text { and } \gamma_{b}>\frac{1}{\beta}-1-\gamma_{d} \tilde{\Phi}+\frac{\tilde{\Phi} \gamma_{d}}{1-\alpha_{\pi}} \text {;or } \\
& \text { 2. } \alpha_{\pi}<1+\frac{\tilde{\Phi} \gamma_{d}}{\frac{1}{\beta}-1-\gamma_{b}-\gamma_{d} \tilde{\Phi}} \text { and } \gamma_{b}>\frac{1}{\beta}-1-\gamma_{d} \tilde{\Phi}+\frac{\tilde{\Phi} \gamma_{d}}{1-\alpha_{\pi}} \text {. }
\end{aligned}
$$

Proof. Analogous to Proposition 1.

First, note that for $\Phi=0$, the requirements stated in Proposition 2 reduce to those given by Proposition 1 . Second, for $\Phi>0$ and $\gamma_{d} \neq 0$, the requirements for $\gamma_{b}$ depend on the value of $\alpha_{\pi}$, and vice versa, which stands in contrast to the requirements found in the benchmark case. This interdependence between $\gamma_{b}$ and $\alpha_{\pi}$ suggests that price level indeterminacy or explosive debt dynamics may ensue, even under active monetary and passive fiscal policy. Third, the parameter $\gamma_{d}$ now enters both the requirements for $\gamma_{b}$ and $\alpha_{\pi}$, indicating that alternative fiscal objectives matter for equilibrium outcomes.

Underlying the change in the policy requirements is a feedback between debt and inflation, which arises due to the presence of sovereign risk. Specifically, a substantial increase in the level of public debt, which raises the probability of sovereign default, $E_{t} \delta_{t+1}$, leads to a reduction in the effective real rate of return on government bonds, $\left(1-E_{t} \delta_{t+1}\right)\left(R_{t} / E_{t} \pi_{t+1}\right)$. Households then reduce their holdings of bonds and raise consumption, which pushes up the price level. This debt-inflation feedback can be 'observed' by substituting the dynamic equation for debt (second equation of [12]) into the dynamic equation for inflation (first equation of [12]) and iterating $k$ periods forward:

$$
\hat{\pi}_{t}=\tilde{\Phi} E_{t} \sum_{i=0}^{k-1} \frac{\hat{b}_{t+i}}{\alpha_{\pi}^{i+1}}+\alpha_{\pi}^{-k} E_{t} \hat{\pi}_{t+k} .
$$


As shown by Equation (13), the extent to which debt dynamics affect inflation is increasing in the degree of sovereign risk, measured by $\Phi$. The ability of the central bank to maintain price stability therefore depends on the fiscal stance with regards to changes in government debt, which in turn is determined by fiscal objectives.

To see how alternative fiscal objectives affect debt dynamics, consider the equilibrium path of real government debt (given by the 'backward' solution of the second equation of [12]):

$$
\hat{b}_{t}=\Gamma^{t} \hat{b}_{0}-\gamma_{d} \sum_{j=0}^{t-1} \Gamma^{j-1} \hat{\pi}_{t-j}
$$

where $\Gamma \equiv 1 / \beta-\gamma_{b}-\gamma_{d} \tilde{\Phi}>0$. If $\Phi>0$, debt dynamics become more unstable when fiscal policy is weak $\left(\gamma_{d}<0\right)$ and less unstable when fiscal policy is strong $\left(\gamma_{d}>0\right)$. We shall elaborate more on these two cases next.

When fiscal policy is weak, the government essentially allows for short-run deviations of the budget deficit from target (e.g. to counteract negative shocks to aggregate demand when fiscal policy is countercyclical). Such fiscal objectives, however, raise concerns regarding debt sustainability, especially in times of sovereign risk, and reduce the demand for government bonds. As explained previously, the reduction in bond holdings is followed by an increase in consumption and inflation. This positive link between debt (sustainability concerns) and inflation, which we define as the "debt-to-inflation channel", is given by Equation (13) and is stronger for higher values of $\Phi$. The higher price level triggers an increase in the policy rate by the central bank, according to the implied Taylor rule, so as to return inflation back to its target level. As the interest rate rises, so does the return on bonds, which makes holding government debt more attractive. However, the higher interest rate also raises public interest expenses, which lead to higher budget deficits and, under weak public finances, a higher level of government debt. This "inflation-to-debt" channel is given by Equation (14). Recall that, in the benchmark case without sovereign risk, the government was able to curtail the increase in debt and achieve long-run debt sustainability (even while allowing for shortrun budget deficits) by setting $\gamma_{b}>1 / \beta-1$. When the risk of sovereign default is absent, households are then willing to hold government bonds in equilibrium, despite the rise in the debt level. In times of sovereign risk, however, this condition for $\gamma_{b}$ may no longer be sufficient to yield debt sustainability, as the increase in the level of debt generates a subsequent rise in inflation through (13). Higher inflation then leads to yet another increase in the interest rate by the central bank and thus higher deficits and debt through (14), which again raises inflation through (13), etc., etc. Hence, in times of sovereign risk and weak fiscal policy, equilibrium outcomes are characterised by more unstable debt dynamics as compared to the benchmark case.

To mitigate the debt-inflation feedback and deliver stable equilibria, fiscal policy must be more passive so as to lower debt sustainability concerns and eliminate the risk of sovereign default, and/or monetary policy must be more active, such that the interest rate rises sufficiently enough to offset the reduction in the return on bonds, thereby reducing consumption and inflation. Furthermore, and in contrast to Leeper, the required passiveness of fiscal policy depends on the activeness of monetary policy, and vice versa; hence, the fiscal-monetary dichotomy is lost. This 
result is formalised by the policy requirements stated in Proposition 2: to guarantee a unique and bounded equilibrium, $\gamma_{b}$ must exceed $1 / \beta-1$ plus a term, $\tilde{\Phi} \gamma_{d} /\left(1-\alpha_{\pi}\right)-\gamma_{d} \tilde{\Phi}$, which is decreasing in $\alpha_{\pi}$ (for $\alpha_{\pi}>1$ and $\gamma_{d}<0$ ). Therefore, the less monetary policy is concerned with inflation developments, the more austere the government must respond to increases in debt to prevent debt from evolving explosively. Likewise, monetary policy must set $\alpha_{\pi}$ higher than 1 plus a term $\tilde{\Phi} \gamma_{d} /\left(1 / \beta-\gamma_{b}-\gamma_{d} \tilde{\Phi}\right)$, which is decreasing in $\gamma_{b}$ (for $\gamma_{b}>1 / \beta-1$ and $\gamma_{d}<0$ ). Thus, the central bank must take on a more aggressive stance towards inflation than prescribed by the Taylor-principle.

The implications of sovereign risk for the policy requirements for equilibrium determinacy and stability under weak fiscal policy are visualised by Figure 2, which, as Figure 1, shows the properties of equilibrium as a function of the fiscal and monetary stance. As can be seen in panel $a$, the range of fiscal and monetary stances that delivers stable and unique equilibria contracts relative to the benchmark case (as reflected by the reduction in the Ricardian and FTPL regions), whereas the likelihood of falling into unstable and indeterminate equilibria rises. The lines that separate active and passive fiscal and monetary policies from Figure 1 are again included to facilitate comparison with the benchmark case. In contrast to the results from the previous section, one could obtain unstable equilibria, even under active monetary and passive fiscal policy. Further, panel $b$ of Figure 2 illustrates that a higher default elasticity $\Phi$ increases the contraction of the regions encompassing stable and unique equilibria: the larger is $\Phi$, the stronger is the debt-to-inflation channel and the greater must be the fiscal and monetary efforts to, respectively, reign in government debt and contain inflation.

Under strong fiscal policy, the debt-to-inflation channel remains the same as before (note that $\gamma_{d}$ does not enter Equation [13]). However, as opposed to the case in which fiscal policy was weak, higher budget deficits are now met by a fiscal contraction, which reduces the debt level. With a lower level of government debt, household concerns regarding fiscal solvency are alleviated and the sovereign default probability falls. The consequent rise in the return on bonds then causes both household consumption and inflation to go down through the debt-to-inflation channel. The reduction in the rate of inflation induces the central bank to lower the interest rate, which reduces the budget deficit and government debt further through (14), leading to a subsequent reduction in sovereign risk and inflation through (13), etc., etc. Stable debt dynamics are therefore more easily obtained in times of sovereign risk and under strong fiscal policy as compared to the benchmark case.

Figure 3 again shows the system's equilibrium properties as a function of the fiscal and monetary stance under sovereign risk, yet this time assuming fiscal policy is strong. As shown by panel $a$, the Ricardian and FTPL regions now expand and merge (the (red-) solid line indicates the border of the FTPL region), whereas the Instability and Indeterminacy regions contract. For given active monetary policy, one can obtain stable and unique equilibria, even if fiscal policy is active; stable and unique equilibria are also feasible when both fiscal and monetary policy are passive. These possibilities arise, since, by committing to a deficit target, the government moderates the accumulation of government debt, which translates into lower inflation through the debt-to-inflation channel and lower in- 
Figure 2: Equilibrium outcome as a function of the fiscal and monetary policy stance under sovereign risk and weak fiscal policy

(a) Effects of weak fiscal policy under sovereign risk

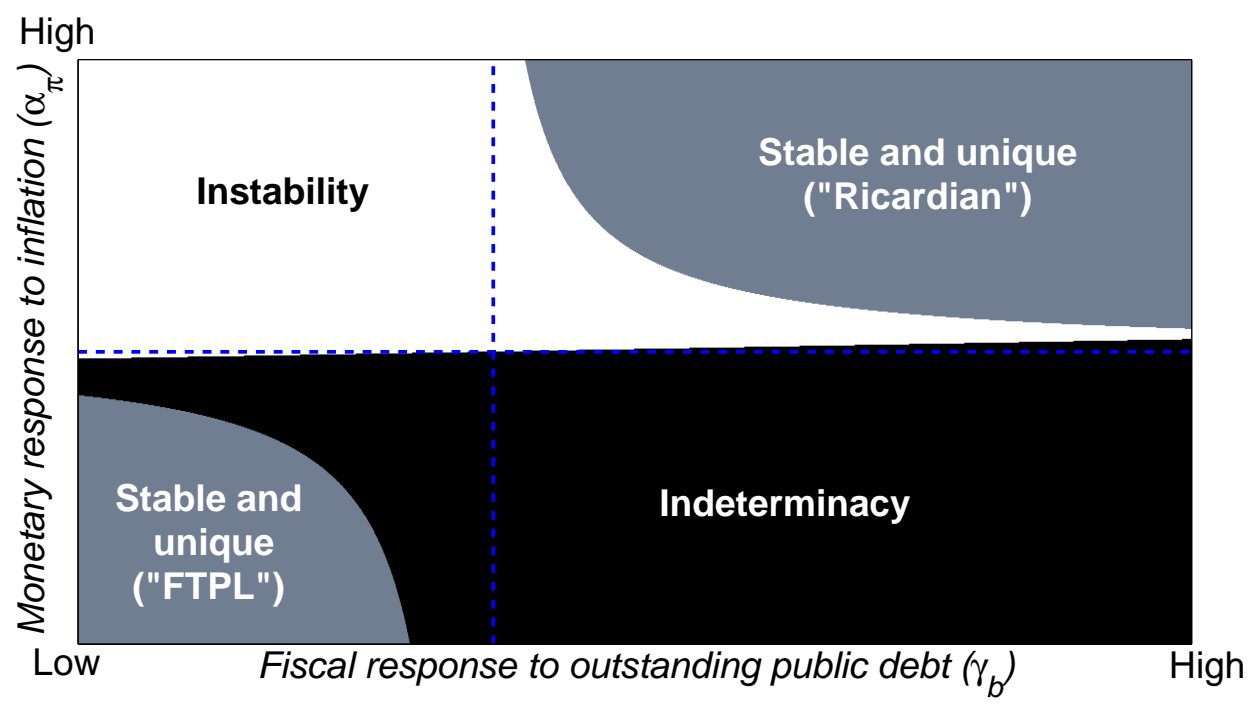

(b) Effects of $\Phi$ under weak fiscal policy

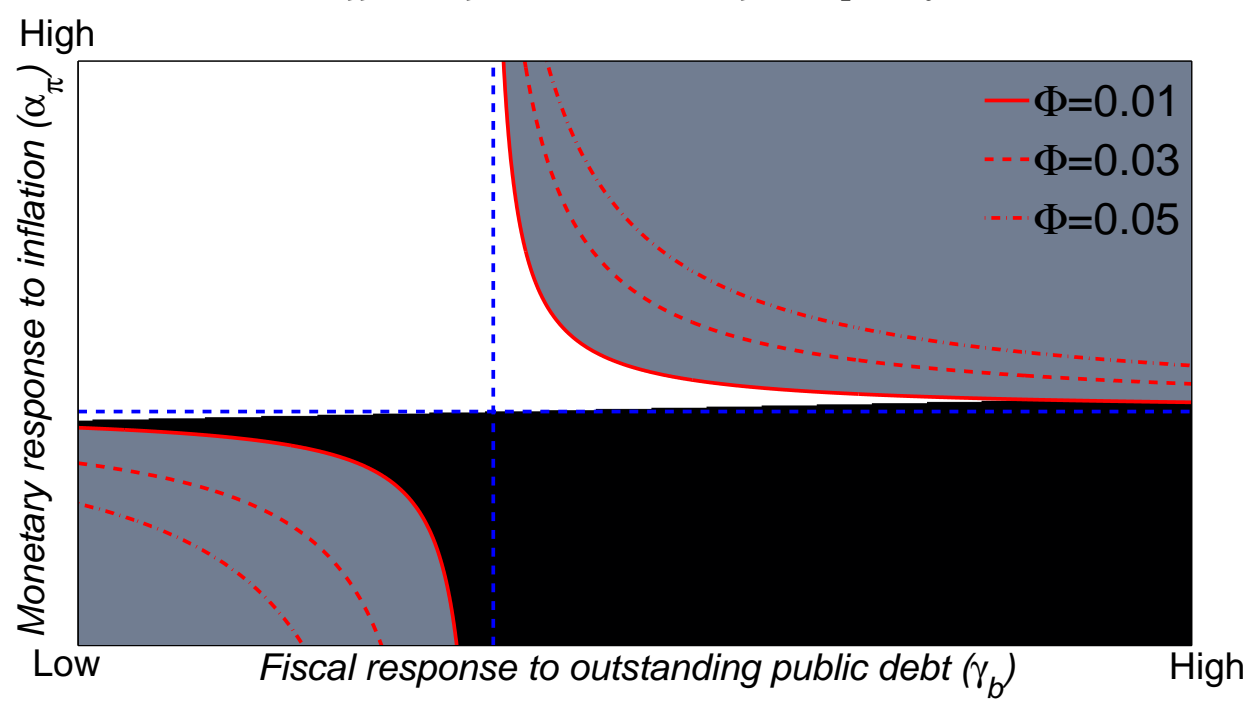

Notes: Figure displays the number of unstable eigenvalues of $A$ as a function of $\gamma_{b}$ and $\alpha_{\pi}$ for $\beta=$ 0.9926: white $=2$, grey $=1$ and black $=0$. 
Figure 3: Equilibrium outcome as a function of the fiscal and monetary policy stance under sovereign risk and strong fiscal policy

(a) Effects of strong fiscal policy under sovereign risk

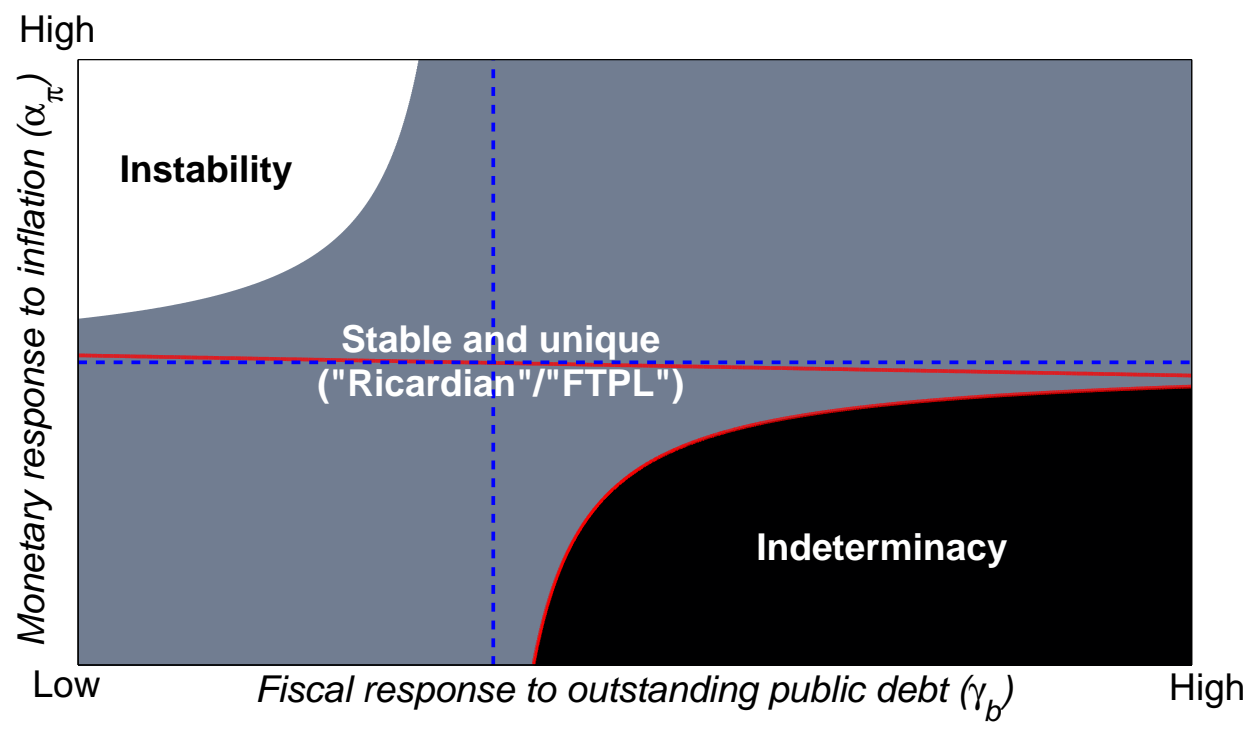

(b) Effects of $\Phi$ under strong fiscal policy

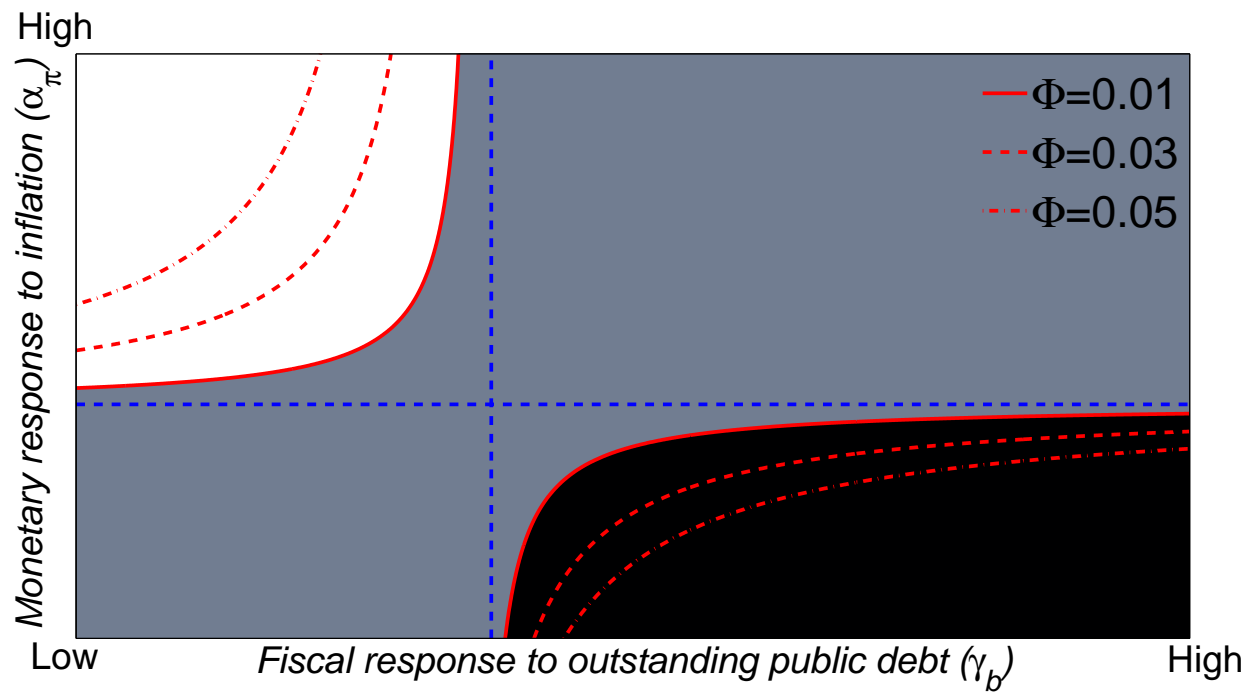

Notes: See notes under Figure 2. The (red) solid line in the figure in panel $a$ refers to the boundary of the FTPL region. 
terest rates and budget deficits through the inflation-to-debt channel; the former raises the scope for price level determinacy, while the latter raises the likelihood of obtaining sustainable paths for government debt. Panel $b$ of Figure 3 shows that the change in the size of the regions is again more pronounced for larger values of the sovereign default elasticity: the higher is $\Phi$, the more responsive are households to a reduction in the default probability and thus the greater is the fall in inflation and interest rates.

Comparing these results with those obtained from the benchmark case reveals a number of important insights. First, unlike in the benchmark case, we find that, in times of sovereign risk, the fiscal-monetary dichotomy seizes to exist. This implies that the required monetary response to inflation depends more heavily on the fiscal stance, while the required fiscal response to changes in government debt depends more heavily on the monetary stance. Therefore, fiscal and monetary policy coordination becomes much more relevant and central bank independence may be impaired, especially when fiscal policy is weak. Although our results are presented within the context of a simple closed endowment economy with flexible prices, they can be shown to be robust to alternative assumptions regarding output dynamics, price adjustments and taxation. Specifically, our results arise from the existence of a feedback between government debt and inflation, which affects the household's optimal intertemporal allocations and thus breaks Ricardian equivalence. ${ }^{2}$

Second, we find fiscal objectives, other than those related to long-run fiscal solvency, to become important determinants of equilibrium characteristics, rather than being completely irrelevant in the absence of sovereign risk. In particular, without the possibility of sovereign default, households are always willing to hold government bonds in equilibrium, provided the government satisfies its intertemporal budget constraint. The latter merely requires the government to focus on long-run debt developments and run a passive fiscal policy. As long as the government remains fiscally solvent in the long run, are short-run debt developments irrelevant for debt sustainability, which allows the government to run budget deficits from time to time. However, if there is a real possibility of sovereign default, then an increase in the budget deficit today raises the probability that the government defaults tomorrow. Hence, short-run debt developments are no longer trivial and the government may find it more difficult to run budget deficits. Instead, the government must take on a more austere stance and strengthen its commitment to debt reduction through a (credible) deficit target; if it does not, then the onus of ensuring stable macroeconomic outcomes falls upon the central bank. Our results therefore rationalises the need (and pleas) for greater measures of fiscal austerity during times of sovereign debt crises and also questions the desirability of expansionary fiscal policy when public finances are weak.

\footnotetext{
${ }^{2}$ In a similar vein, Canzoneri and Diba (2005) and Linnemann and Schabert (2012) introduce a link between government debt and inflation which arises from transactions services provided by bonds and examine how this type of debt non-neutrality affects the determinacy constraints imposed on fiscal and monetary policy interactions. They find that a positive sunspot shock to inflation, which reduces the real value of debt and raises the return on bonds, reduces aggregate demand and thereby the price level; stable and unique equilibria can therefore be achieved, even when monetary policy violates the Taylor-principle. One could also derive these results by assuming households are finitely lived, such that government bonds generate wealth effects, as shown by Piergallini (2005).
} 


\section{Application: alternative monetary objectives}

We closed the previous section with the observation that budget deficits are trivial in the absence of sovereign risk, yet become quite undesirable in times when public finances are weak and lenders form expectations of sovereign default. In particular, in the presence of sovereign risk, higher budget deficits raise the likelihood of creating unstable macroeconomic conditions and warrant the adoption of a credible deficit target. However, if the government is unable (or unwilling) to shift from a weak to a strong fiscal policy, what options are at the central bank's disposal to improve upon the situation? In this section, we shall address this question within the context of the same model presented in Section 2.

From our discussion in Section 3, we know that sovereign risk distorts the household's optimal consumption-savings decision through the debt-to-inflation channel. To see how the central bank can eliminate this distortion, we start by amending the specification of the monetary policy rule so as to allow the central bank to respond to fiscal variables (see also Schabert, 2006). To this end, we replace the monetary rule given by (7) by the following rule:

$$
R_{t}=\widetilde{\alpha}_{\pi}\left(\pi_{t}-\pi^{*}\right)+\widetilde{\alpha}_{b}\left(b_{t}-b^{*}\right),
$$

or, in log-linearised form:

$$
\hat{R}_{t}=\alpha_{\pi} \hat{\pi}_{t}+\alpha_{b} \hat{b}_{t}
$$

where $\alpha_{\pi}$ is defined as before and $\alpha_{b} \equiv \widetilde{\alpha}_{b} b / R$ measures the degree to which the central bank responds to changes in government debt. Regarding the latter, we define the following:

Definition 4. When $\alpha_{b}>0$, monetary policy is called "punishing". When $\alpha_{b}<0$, monetary policy is called "accommodative".

Proposition 3. Given $\Phi \in(0,1)$, a fiscal rule of the form (5) and a monetary rule of the form (15), a stable and unique rational expectations equilibrium is obtained if and only if the policy parameters $\alpha_{\pi}$ and $\gamma_{b}$ obey:

$$
\begin{aligned}
& \text { 1. } \alpha_{\pi}>1+\frac{\left(\tilde{\Phi}-\alpha_{b}\right) \gamma_{d}}{\frac{1}{\beta}-1-\gamma_{b}-\gamma_{d} \tilde{\Phi}} \text { and } \gamma_{b}>\frac{1}{\beta}-1-\gamma_{d} \tilde{\Phi}+\frac{\left(\tilde{\Phi}-\alpha_{b}\right) \gamma_{d}}{1-\alpha_{\pi}} \text {;or } \\
& \text { 2. } \alpha_{\pi}<1+\frac{\left(\tilde{\Phi}-\alpha_{b}\right) \gamma_{d}}{\frac{1}{\beta}-1-\gamma_{b}-\gamma_{d} \tilde{\Phi}} \text { and } \gamma_{b}<\frac{1}{\beta}-1-\gamma_{d} \tilde{\Phi}+\frac{\left(\tilde{\Phi}-\alpha_{b}\right) \gamma_{d} R}{1-\alpha_{\pi}} \text {. }
\end{aligned}
$$

Proof. Analogous to Proposition 1.

Proposition 3 finds that, through appropriate adjustment of the parameter $\alpha_{b}$, the central bank is able to mitigate, or even eliminate, the effects of sovereign risk on the equilibrium determinacy and stability requirements for fiscal and monetary policy. Specifically, if $\alpha_{b}=\tilde{\Phi}$, the requirements for $\alpha_{\pi}$ are once again independent from $\gamma_{b}$, and vice versa; in other words, in the presence of sovereign risk, the fiscalmonetary dichotomy can be recovered, as long as monetary policy is punishing and $\alpha_{b}=\tilde{\Phi}$.

To understand this result, note that, by raising the interest rate upon an increase in government debt by $\tilde{\Phi}$, the central bank completely offsets the reduction in the effective real rate of return on bonds induced by the rise in sovereign risk. 
Figure 4: Equilibrium outcome as a function of the fiscal and monetary policy stance under weak fiscal policy and punishing monetary policy

(a) Case 1: $\alpha_{b}=\tilde{\Phi}$

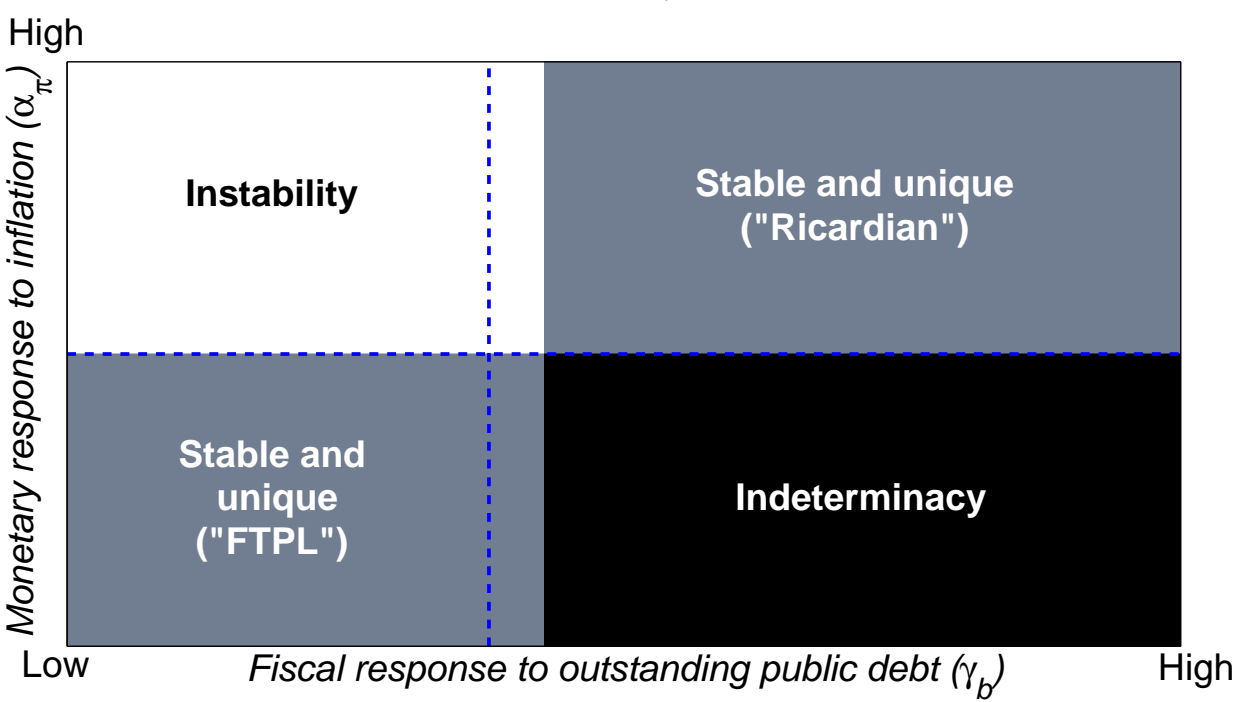

(b) Case 2: $\alpha_{b}=2 \tilde{\Phi}$

High

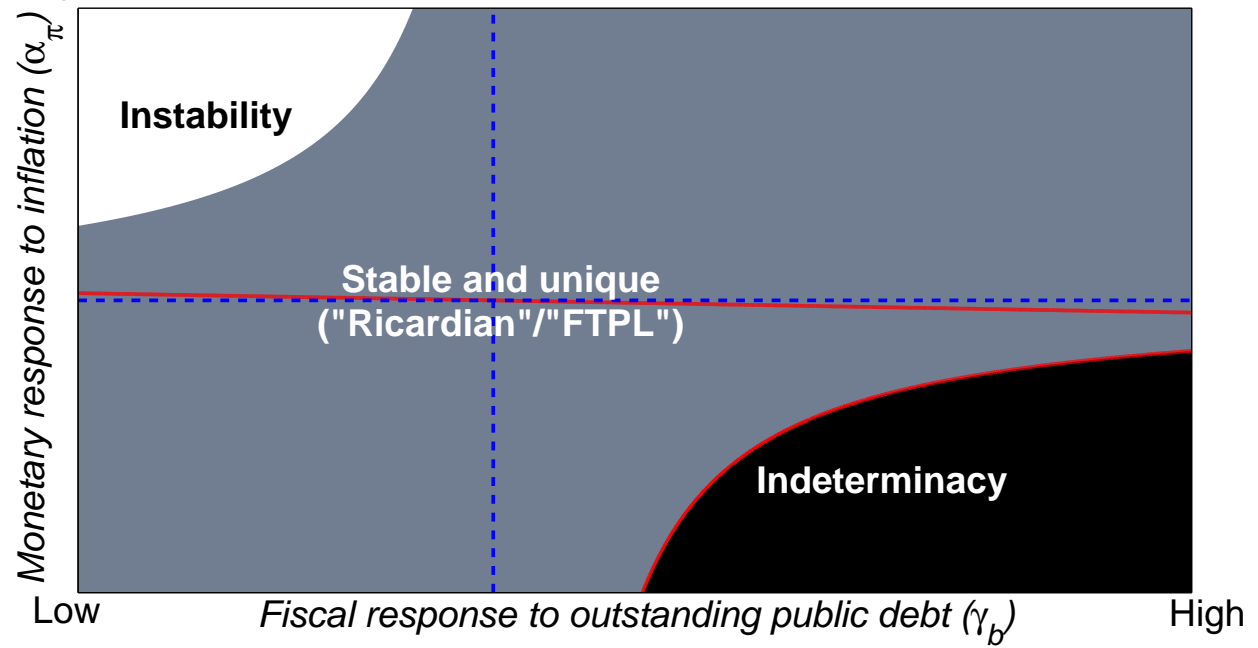

Notes: Figure displays the number of unstable eigenvalues of $A$ as a function of $\gamma_{b}$ and $\alpha_{\pi}$ for $\beta=$ 0.9926 : white $=2$, grey $=1$ and black $=0$. The (red) solid line in the figure in panel $b$ refers to the boundary of the FTPL region. 
As such, a change in the level of government debt, and thus in sovereign risk, does not provoke a response from household consumption, nor from inflation. This can be seen by substituting $\hat{R}_{t}$ from (16) in the household's Euler equation, (10), while assuming $\alpha_{b}=\tilde{\Phi}$ :

$$
\alpha_{\pi} \hat{\pi}_{t}=E_{t} \hat{\pi}_{t+1} .
$$

The equation shows that government debt no longer interacts with intertemporal margins and therefore does not distort the household's optimal consumption-savings decision. Since inflation dynamics are decoupled from debt dynamics, the fiscalmonetary dichotomy reappears: as in the benchmark case, the price level is uniquely determined, and consistent with the equilibrium paths of the remaining endogenous variables, as long as $\alpha_{\pi}>1$ and regardless of the fiscal policy stance.

Figure 4 shows the equilibrium properties of the system, with the new monetary policy rule, as a function of the monetary and fiscal stance under weak fiscal policy and punishing monetary policy. As can be seen from panel $a$, in which the central bank sets $\alpha_{b}=\tilde{\Phi}$, the constraints on monetary policy are orthogonal to the fiscal stance: as long as $\alpha_{\pi}>1$, the price level sequence will be uniquely determined, even when $\gamma_{d}<0$ and irrespective of $\gamma_{b}$. Panel $b$ shows that the central bank can also raise the scope for equilibrium determinacy and stability by being more punishing and setting $\alpha_{b}$ higher, for instance $\alpha_{b}=2 \tilde{\Phi}>\tilde{\Phi}$. Intuitively, a given sunspot shock to inflation, which raises interest rates through the implied monetary feedback rule, leads to an increase in the budget deficit and government debt. The subsequent rise in sovereign risk, which tends to reduce the return on bonds, is offset by more than one-for-one by an increase in the policy rate. The return on bonds therefore rises and consumption and inflation both fall. As the price level converges back towards steady state, the interest rate falls, which in turn reduces the budget deficit and government debt, causing the interest rate to fall further, etc., etc. Therefore, both stable and unique equilibria are more easily obtained when monetary policy is punishing and fiscal policy weak.

\section{Conclusion and discussion}

Sovereign debt crises are often associated with greater (pleas for) fiscal austerity measures and concerns regarding runaway inflation. To understand the rationale underlying these shifts in fiscal and monetary policy, we have examined the effects of sovereign risk on the constraints imposed by macroeconomic stability on fiscal and monetary policy. We showed that, in the presence of sovereign risk, a feedback between inflation and government debt emerges, such that inflation and debt dynamics are determined jointly. The ability of the central bank to maintain price stability therefore depends more heavily on the fiscal stance, while the government's ability to ensure long-run fiscal solvency depends more heavily on the monetary stance.

Our results emphasized the merits of alternative fiscal objectives in times of sovereign risk. In particular, when government debt repayment is uncertain, commitment to long-run debt sustainability may no longer be a sufficient condition to deliver macroeconomic stability. Instead, we have shown that the possibility of provoking a self-reinforcing cycle of rising debt and inflation grows, unless the government adopts a (credible) deficit target. Particularly, a restriction to the budget 
deficit signals to holders of government bonds the government's commitment to contain the accumulation of debt, thereby raising the scope for long-run fiscal solvency. In addition, by lowering the probability of sovereign default, a deficit target reduces consumption and thus accommodates monetary policy in keeping inflation low. Without such a restriction to the budget deficit, fiscal policy diminishes the range of the monetary stance that achieves price level determinacy and thus impairs central bank independence.

A commonly heard objection against deficit restrictions is that they reduce the scope for economic stabilisation policy and promote pro-cyclical fiscal policies (which may lead to greater output volatility). Our model, however, suggests that, in the absence of sovereign risk, the government is merely required to remain fiscally solvent in the long run in order to obtain stable macroeconomic conditions. Since the requirements for equilibrium stability are independent from the marginal response to the deficit, there is room for short-run cyclical fluctuations in the budget surplus so as to absorb shocks (e.g. through automatic stabilisers). However, when the economy is facing sovereign risk, neglecting deficits can result into unstable dynamics. In line with Corsetti et al. (2013), our results suggest that under such circumstances, a pro-cyclical fiscal policy supports macroeconomic stability. Whether or not budgetary constraints lead to higher welfare in times of sovereign risk is an interesting topic which we leave for future work. 


\section{References}

Bi, H. (2012). Sovereign default risk premia, fiscal limits, and fiscal policy. European Economic Review, 56:389-410.

Bi, H., Leeper, E. M., and Leith, C. (2010). Stabilization versus sustainability: Macroeconomic policy tradeoffs. Unpublished Manuscript.

Blanchard, O. J. and Kahn, C. M. (1980). The solution of linear difference models under rational expectations. Econometrica: Journal of the Econometric Society, pages 1305-1311.

Calvo, G. A. (1983). Staggered prices in a utility-maximizing framework. Journal of Monetary Economics, 12(3):383-398.

Canzoneri, M. and Diba, B. (2005). Interest rate rules and price determinacy: the role of transactions services of bonds. Journal of Monetary Economics, 52(2):329 343.

Clarida, R. H., Galí, J., and Gertler, M. (1999). The science of monetary policy: a New Keynesian perspective. Journal of Economic Literature, 37:1661-1707.

Collignon, S. (2012). Fiscal policy rules and the sustainability of public debt in Europe. International Economic Review, 53(2):539-567.

Corsetti, G., Kuester, K., Meier, A., and Müller, G. J. (2013). Sovereign risk and belief-driven fluctuations in the euro area. Journal of Monetary Economics.

Davig, T., Leeper, E. M., and Walker, T. B. (2010). "Unfunded liabilities" and uncertain fiscal financing. Journal of Monetary Economics, 57(5):600-619.

Davig, T., Leeper, E. M., and Walker, T. B. (2011). Inflation and the fiscal limit. European Economic Review, 55(1):31-47.

Eaton, J. and Gersovitz, M. (1981). Debt with potential repudiation: theoretical and empirical analysis. The Review of Economic Studies, pages 289-309.

Galí, J. and Monacelli, T. (2005). Monetary policy and exchange rate volatility in a small open economy. The Review of Economic Studies, 72(3):707-734.

Leeper, E. M. (1991). Equilibria under 'active' and 'passive' monetary and fiscal policies. Journal of Monetary Economics, 27(1):129-147.

Leith, C. and von Thadden, L. (2008). Monetary and fiscal policy interactions in a New Keynesian model with capital accumulation and non-Ricardian consumers. Journal of Economic Theory, 140(1):279-313.

Linnemann, L. (2006). Interest rate policy, debt, and indeterminacy with distortionary taxation. Journal of Economic Dynamics and Control, 30(3):487-510.

Linnemann, L. and Schabert, A. (2012). Fiscal rules, interest payments on debt, and the irrelevance of the Taylor principle. Scottish Journal of Political Economy, 59(3):250-265. 
Piergallini, A. (2005). Equilibrium determinacy under monetary and fiscal policies in an overlapping generations model. Economic Notes, 34(3):313-330.

Schabert, A. (2006). Central bank instruments, fiscal policy regimes, and the requirements for equilibrium determinacy. Review of Economic Dynamics, 9(4):742-762.

Schabert, A. and van Wijnbergen, S. (2011). Sovereign default and the stability of inflation targeting regimes. Tinbergen Institute Discussion Papers 11-064/2/ DSF20.

Sims, C. A. (1994). A simple model for study of the determination of the price level and the interaction of monetary and fiscal policy. Economic Theory, 4(3):381-399.

Taylor, J. B. (1993). Discretion versus policy rules in practice. In CarnegieRochester conference series on public policy, volume 39, pages 195-214. Elsevier.

Uribe, M. (2006). A fiscal theory of sovereign risk. Journal of Monetary Economics, 53(8):1857-1875.

Woodford, M. (2001). Fiscal requirements for price stability. Journal of Money, Credit and Banking, 33(3):669-728. 


\section{A Extension of the model}

In this section, we amend the endowment economy model presented in Section 2 by allowing for endogenous production, price rigidities and distortionary income taxes. We introduce a production sector, which hires labour services from households to produce goods, and impose restrictions on price setting by firms; the public sector remains unaltered. After expressing the log-linearised version of the new model in state-space form, we examine the equilibrium stability and determinacy requirements for fiscal and monetary policy and demonstrate how these requirements change after introducing sovereign risk. Throughout, we shall make the same modelling assumptions regarding sovereign default and the policy feedback rules as in Section 2.2.1 and 2.2.2, respectively.

\section{A.1 A New Keynesian model with sovereign risk}

\section{A.1.1 Households}

The infinitely-lived, representative household now chooses consumption, $c_{t}$, and hours worked, $n_{t}$, in order to maximise expected life-time utility, i.e.

$$
E_{0} \sum_{k=0}^{\infty} \beta^{k}\left(\frac{c_{t+k}^{1-\sigma}}{1-\sigma}-\frac{n_{t+k}^{1+\varphi}}{1+\varphi}\right),
$$

where $\sigma>0$ is the inverse of the household's intertemporal elasticity of substitution and $\varphi>0$ is the inverse of the Frisch elasticity of labour supply. Rather than receiving a constant endowment, household income consists of income from labour services, $W_{t} n_{t}$, where $W_{t}$ defines the nominal wage rate, and firm profits, $\Psi_{t}=$ $\int_{0}^{1} \Psi_{t}(i) d i$ where $i \in[0,1]$ is a firm-specific index. The household must pay a portion of its labour and profit income to the government, i.e. $P_{t} \tau_{t} \equiv P_{t} \tau_{t}^{d}\left(w_{t} n_{t}+\Psi_{t}\right)$, where $\tau_{t}^{d}$ is a time-varying tax rate and $w_{t} \equiv W_{t} / P_{t}$ the real wage rate. As before, the household can invest in one-period government discount bonds, on which it receives the policy rate, $R_{t}-1$, conditional on the risk of sovereign default. The household's budget constraint reads:

$$
P_{t} c_{t}+B_{t}+P_{t} \tau_{t}=\left(1-\delta_{t}\right) R_{t-1} B_{t-1}+W_{t} n_{t}+P_{t} \Psi_{t}
$$

Maximising (17), subject to (18) and an appropriate transversality condition and taking prices, the tax rate, the wage rate, the sovereign default probability, firm profits and initial asset holdings, $B_{-1}$, as given, results into the following first-order conditions:

$$
\begin{aligned}
n_{t}^{\varphi} & =\left(1-\tau_{t}^{d}\right) w_{t} c_{t}^{-\sigma} \\
c_{t}^{-\sigma} & =\beta E_{t}\left[\left(1-\delta_{t+1}\right) \frac{R_{t}}{\pi_{t+1}} c_{t+1}^{-\sigma}\right] .
\end{aligned}
$$

Equation (19) describes the household's optimal intratemporal decision, relating the marginal rate of substitution between consumption and leisure to the real wage rate; equation (20) is the household Euler equation, relating expected consumption growth to the effective real rate of return on government bonds. 


\section{A.1.2 Firms}

The production sector consists of two types of firms: final goods firms, operating in perfectly competitive markets, and intermediate goods firms, operating in monopolistically competitive markets.

The final goods firm combines intermediate goods $y_{t}(i)$, where $i=1,2, \ldots$, purchased from intermediate goods firm $i$, to produce the final good, $y_{t}$, using a standard CES production function, i.e.:

$$
y_{t}=\left[\int_{0}^{1} y_{t}(i)^{\frac{\epsilon-1}{\epsilon}} d i\right]^{\frac{\epsilon}{\epsilon-1}}
$$

where $\epsilon>1$ is the elasticity of substitution between intermediate goods. Minimising costs of assembling $y_{t}$, subject to (21), results in the optimal demand schedule for $y_{t}(i)$ and an expression for the aggregate price level, $P_{t}$ :

$$
\begin{aligned}
y_{t}(i) & =\left[\frac{P_{t}(i)}{P_{t}}\right]^{-\epsilon} y_{t}, \\
P_{t} & =\left[\int_{0}^{1} P_{t}(i)^{1-\epsilon} d i\right]^{\frac{1}{1-\epsilon}} .
\end{aligned}
$$

Intermediate goods firms, on the other hand, use the following linear, constant returns to scale production technology with only labour as an input factor in the production process:

$$
y_{t}(i)=n_{t}(i)
$$

where $n_{t}(i)$ is the amount of labour demanded by firm $i$. Optimal labour demand satisfies:

$$
m c_{t}(i)=w_{t},
$$

where $m c_{t}(i)$ denotes real marginal costs. Rigidities are introduced in the prices of intermediate goods by assuming staggered price setting (Calvo, 1983). Specifically, in every period, a randomly selected portion of intermediate goods firms, $1-\theta$, is able to adjust prices in response to demand and supply shocks, while the remaining share, $\theta \in[0,1)$, is unable to adjust and keeps prices unchanged. Hence, the parameter $\theta$, which is independent of the time elapsed since the previous price setting, is a measure of price rigidity and the average duration of a 'price contract' is $\sum_{k=0}^{\infty} \theta^{k} \Rightarrow 1 /(1-\theta)$. Firms that are able to adjust prices do so with the aim of maximising current and expected future profits, i.e.:

$$
E_{0} \sum_{k=0}^{\infty} \theta^{k} Q_{t, t+k}\left[\bar{P}_{t} y_{t, t+k}(i)-W_{t+k} n_{t, t+k}(i)\right],
$$

where $\bar{P}_{t}$ is the optimal re-set price ${ }^{3}$ and $Q_{t, t+k} \equiv \beta^{k}\left(1-\delta_{t+k}\right)\left(c_{t+k} / c_{t}\right)^{-\sigma} / \pi_{t+k}$ is the stochastic discount factor for nominal pay-offs in period $t+k$ (see [20]). Subject to (22), (24) and (25) and taking the wage rate and the probability of non-price adjustment as given, profit maximisation leads to the following optimal re-set price:

$$
\bar{P}_{t}=\mathcal{M} \frac{E_{0} \sum_{k=0}^{\infty}(\theta \beta)^{k}\left(1-\delta_{t+k}\right) P_{t+k}^{\epsilon} c_{t+k}^{-\sigma} y_{t+k} m c_{t+k}}{E_{0} \sum_{k=0}^{\infty}(\theta \beta)^{k}\left(1-\delta_{t+k}\right) P_{t+k}^{\epsilon-1} c_{t+k}^{-\sigma} y_{t+k}} .
$$

\footnotetext{
${ }^{3}$ Note that the optimal re-set price is not firm-specific, due to symmetry among firms.
} 
According to (26), the optimal re-set price is a mark-up $\mathcal{M} \equiv \epsilon /(\epsilon-1)$ over current and expected real marginal costs. Note that, under flexible prices, $\theta \rightarrow 0$ and $\bar{P}_{t}=P_{t}$ for all $t$, such that $(26)$ reduces to $m c_{t}=1 / \mathcal{M}$.

\section{A.1.3 Equilibrium}

In equilibrium, the economy's aggregate resource constraint, $y_{t}=c_{t}+g$, must be satisfied and the government bonds market clears. Furthermore, labour market clearing implies $n_{t}=\int_{0}^{1} y_{t}(i) d i=y_{t} \mathcal{D}=y_{t}$, where $\mathcal{D} \equiv \int_{0}^{1}\left[\frac{P_{t}(i)}{P_{t}}\right]^{-\epsilon} d i$ is a measure of price dispersion whose equilibrium variations around a perfect foresight steady state are of second order, i.e. $Z_{t} \approx 1$ (see Galí and Monacelli, 2005).

Equilibrium is then given by a sequence of $c_{t+k}, n_{t+k}, y_{t+k}, w_{t+k}, b_{t+k}, \delta_{t+k}, \pi_{t+k}$, $\tau_{t+k}^{d}$ and $R_{t+k}$, satisfying the household's first-order conditions, (19) and (20), the aggregate price index, (23), the intermediary goods firm's optimal pricing decision, (26), the government budget constraint, (4), the two policy rules, (5) and (7), and exogenous sequences for government consumption, $g$, and the fiscal limit, for all $k$.

\section{A.2 Equilibrium stability and determinacy under sovereign risk}

\section{A.2.1 Dynamics of the model}

For simplicity, and without loss of generality, we normalise government spending to zero, i.e. $g=0$. Log-linearising the equilibrium conditions around the constant steady state then yields the following system in the endogenous variables $\left\{\hat{c}_{t}, \hat{w}_{t}, \hat{y}_{t}, \hat{\pi}_{t}, \hat{\tau}_{t}^{d}, \hat{R}_{t}, \hat{b}_{t}\right\}:$

$$
\begin{aligned}
\sigma \hat{c}_{t} & =\sigma E_{t} \hat{c}_{t+1}-(1-\Phi)\left(\hat{R}_{t}-E_{t} \hat{\pi}_{t+1}\right)+\Phi \hat{b}_{t} \\
\varphi \hat{y}_{t}+\sigma \hat{c}_{t} & =\hat{w}_{t}-\mu \hat{\tau}_{t}^{d} \\
\hat{y}_{t} & =\hat{c}_{t} \\
\hat{\pi}_{t} & =\lambda \hat{w}_{t}+\beta E_{t} \hat{\pi}_{t+1} \\
\hat{\tau}_{t}^{d}+\hat{y}_{t} & =\frac{b}{\tau^{d} y}\left(\gamma_{b} \hat{b}_{t-1}+\gamma_{d} \hat{R}_{t-1}\right) \\
\hat{R}_{t} & =\alpha_{\pi} \hat{\pi}_{t} \\
\hat{b}_{t}+\frac{\tau^{d} y}{b}\left(\hat{\tau}_{t}^{d}+\hat{y}_{t}\right) & =\left(\frac{1-\Phi}{\beta}\right)\left(\hat{b}_{t-1}+\hat{R}_{t-1}-\hat{\pi}_{t}\right) .
\end{aligned}
$$

where $\mu \equiv \tau^{d} /\left(1-\tau^{d}\right)$ and $\lambda \equiv(1-\theta)(1-\theta \beta) / \theta$.

After appropriate substitutions, and using the auxiliary variable $\hat{\pi}_{t}^{\prime}=\hat{\pi}_{t}$, the system given by (27)-(33) can be reduced to the following $4 \times 4$ system:

$$
K\left[\begin{array}{c}
E_{t} \hat{\pi}_{t+1} \\
E_{t} \hat{c}_{t+1} \\
\hat{b}_{t} \\
\hat{\pi}_{t}^{\prime}
\end{array}\right]=L\left[\begin{array}{c}
\hat{\pi}_{t} \\
\hat{c}_{t} \\
\hat{b}_{t-1} \\
\hat{\pi}_{t-1}^{\prime}
\end{array}\right],
$$


Figure 5: Equilibrium outcome as a function of the fiscal and monetary policy stance, without sovereign risk

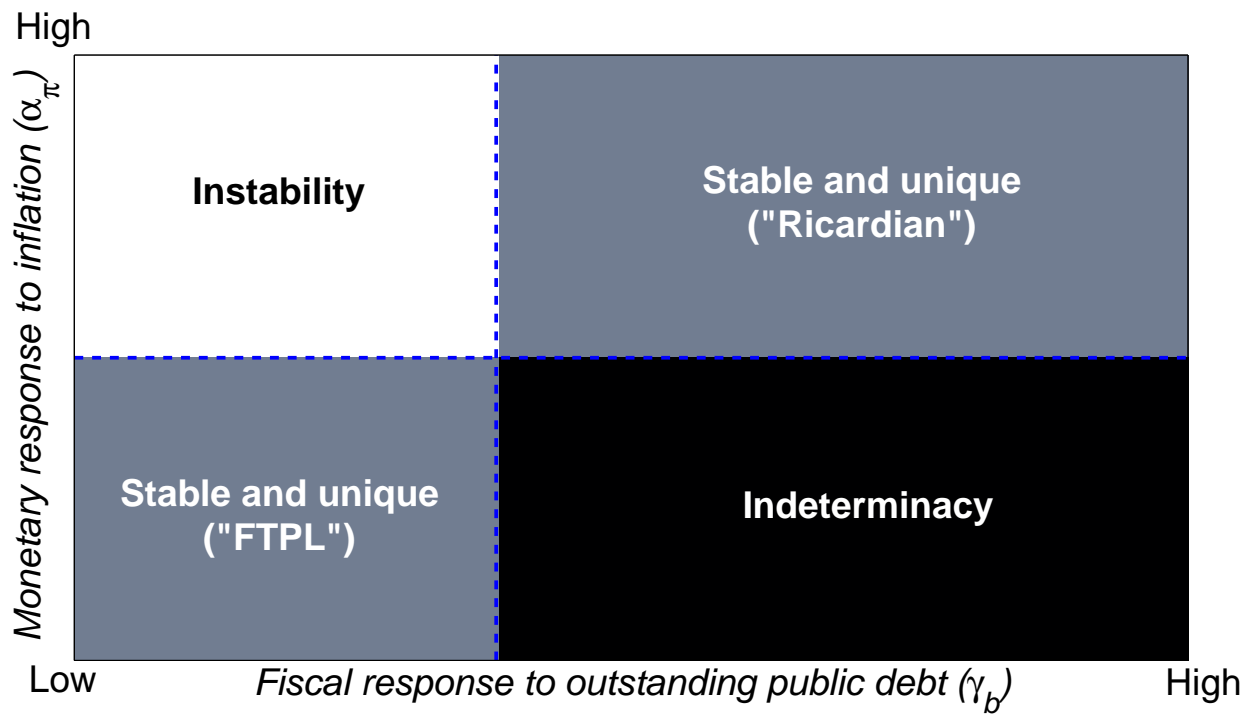

Notes: Figure displays the number of unstable eigenvalues of $K^{-1} L$ as a function of $\gamma_{b}$ and $\alpha_{\pi}$ for $\beta=0.9926, \varphi=3, \sigma=1, b / y=0.6$ (annually) and $\tau^{d}=0.3$ : white $=3$, grey $=2$ and black $=1$.

where

$$
\begin{aligned}
K & \equiv\left[\begin{array}{cccc}
\beta & 0 & 0 & 0 \\
1-\Phi & \sigma & \Phi & 0 \\
0 & 0 & 1 & 0 \\
0 & 0 & 0 & 1
\end{array}\right], \\
L & \equiv\left[\begin{array}{cccc}
1 & -\lambda \kappa & -\lambda \mu \frac{b}{\tau^{d} y} \gamma_{b} & -\lambda \mu \frac{b}{\tau^{d} y} \gamma_{d} \alpha_{\pi} \\
(1-\Phi) \alpha_{\pi} & \sigma & 0 & 0 \\
-\left(\frac{1-\Phi}{\beta}\right) & 0 & \frac{1-\Phi}{\beta}-\gamma_{b} & \left(\frac{1-\Phi}{\beta}-\gamma_{d}\right) \alpha_{\pi} \\
1 & 0 & 0 & 0
\end{array}\right],
\end{aligned}
$$

and where $\kappa \equiv \varphi+\sigma-\mu$. The system given by (34) contains two forward-looking variables, $\hat{\pi}_{t}$ and $\hat{c}_{t}$, and one predetermined variable, $\hat{b}_{t}$. Therefore, to obtain equilibrium stability and determinacy, the matrix $K^{-1} L$ must contain two unstable eigenvalues and one stable eigenvalue (by definition, the eigenvalue corresponding to $\hat{\pi}_{t}^{\prime}$ equals one).

\section{A.2.2 Results}

To assess the implications of sovereign risk for macroeconomic stabilisation policy, we shall rely on numerical solutions. Specifically, as in Section 3, we plot the number of unstable eigenvalues of $K^{-1} L$ as a function of the fiscal and monetary policy stance, captured by $\gamma_{b}$ and $\alpha_{\pi}$, respectively.

The results for the benchmark case, in which there is no sovereign risk and $\Phi=0$, are presented by Figure 5 . We see that in this case, the results from Leeper 
Figure 6: Equilibrium outcome as a function of the fiscal and monetary policy stance under sovereign risk

(a) Weak fiscal policy

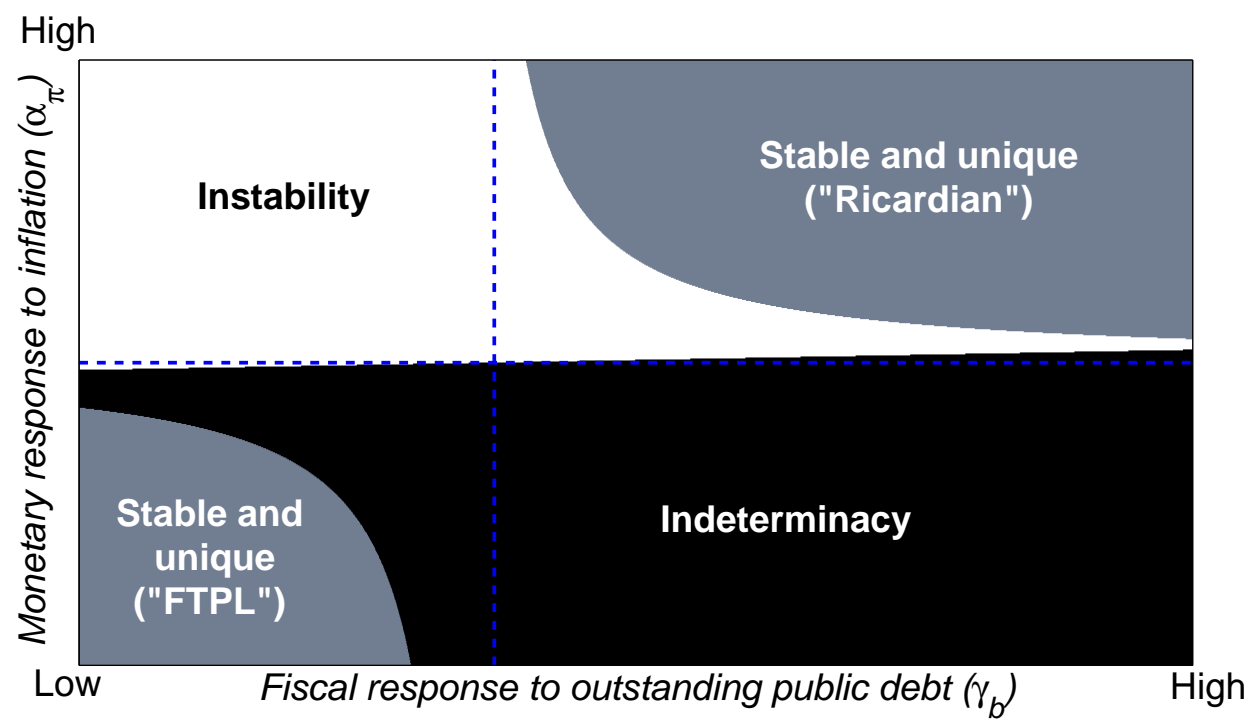

(b) Strong fiscal policy

High

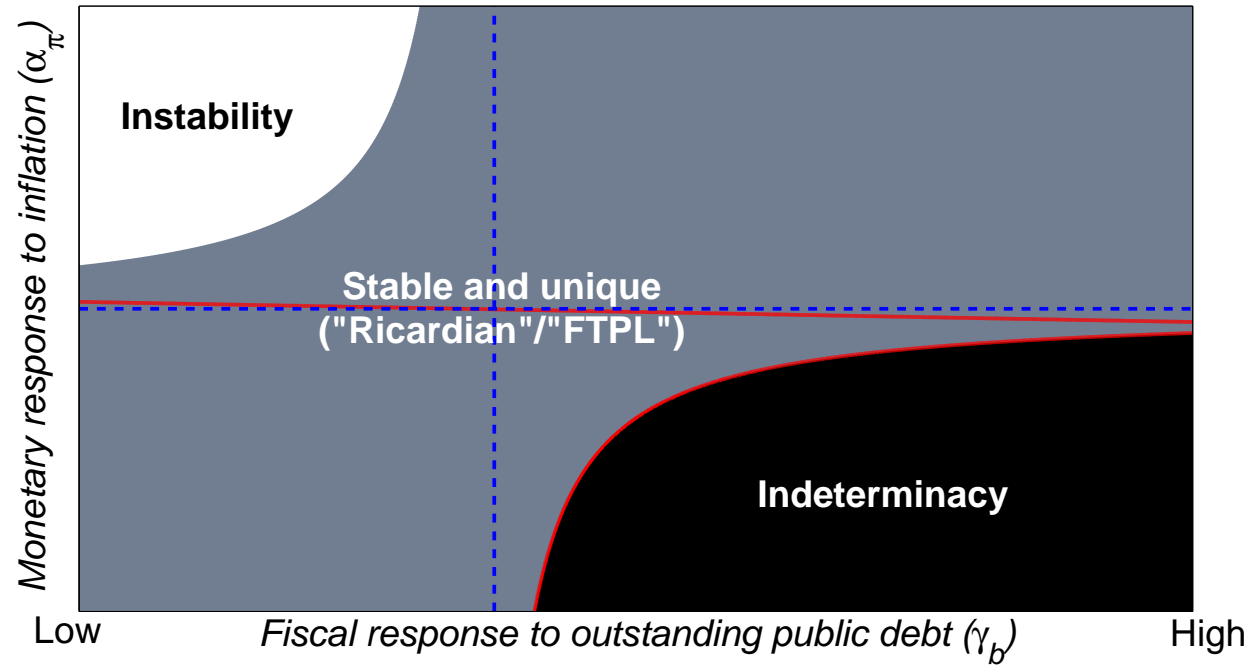

Notes: See notes under Figure 5. The (red) solid line in the figure in panel $b$ refers to the boundary of the FTPL region. 
hold and the fiscal-monetary dichotomy applies: as long as fiscal policy is passive and monetary policy active are debt dynamics stable and is the price level sequence uniquely determined, regardless of the relative weights of the two policy objectives. In addition, the fiscal-monetary dichotomy maintains, despite the government's desire to allow for short-run budget deficits and run countercyclical fiscal policy.

In Figure 6, we show the results for the case in which the economy faces sovereign risk. In panel $a$, fiscal policy is weak and the stability and determinacy regions contract compared to the benchmark case, whereas the scope for obtaining unstable and indeterminate equilibria rises. Furthermore, the required passiveness of fiscal policy to obtain stable equilibria now depends on the size of $\alpha_{\pi}$, even beyond $\alpha_{\pi}>1$. Merely maintaining the growth rate of government debt below the steady-state real risk-free interest rate may therefore no longer satisfy the public's intertemporal budget constraint. As explained in Section 3, the rise in sovereign risk reduces the willingness to hold government bonds and induces an increase in private spending and inflation. The rise in inflation then prompts the central bank to raise its policy rate, which leads to higher public interest payments and a higher budget deficit, further raising debt sustainability concerns. The economy therefore threatens to fall into a self-reinforcing cycle of rising debt and inflation, unless the government takes appropriate steps to contain the accumulation of government debt or if the decline in the return on bonds can be offset through a sufficient increase in the nominal interest rate by the central bank.

In panel $b$ of Figure 6, fiscal policy is strong and we observe an increase in the stability and determinacy regions. The tougher stance of the government with regards to changes in the budget deficit relieves concerns amongst lenders about future sovereign defaults and induces them to hold bonds and consume less. Inflation therefore falls and the central bank lowers its policy rate, which reduces the budget deficit and thereby also the risk of sovereign default and inflation, etc., etc. By committing to a deficit target, the government raises the scope for debt sustainability. In addition, since the government accommodates monetary policy in maintaining low inflation, price level determinacy can be obtained, even when the central bank violates the Taylor-principle.

The figures displayed in Figures 5 and 6 are identical to those presented in Section 3 and convey the same message: in the presence of sovereign risk, fiscal and monetary policy coordination becomes much more relevant for equilibrium outcomes, especially when fiscal policy is weak and short-run budget deficits are neglected. 